\title{
Relação Umidade: Proteína em peitos de frango de corte acometidos com defeitos
}

\section{musculares}

\author{
Moisture: Protein Ratio in broiler chicken breasts affected with muscle defects \\ Proporción Humedad: Proteína en pechugas de pollo de engorde afectadas con defectos musculares
}

Recebido: 15/01/2022 | Revisado: 23/01/2022 | Aceito: 25/01/2022 | Publicado: 26/01/2022

Tainá Simonetti

ORCID: https://orcid.org/0000-0003-1175-9998 Universidade Federal do Rio Grande do Sul, Brasil E-mail: taina_simonetti@hotmail.com.br

Thiago Langer Lantmann

ORCID: https://orcid.org/0000-0001-8762-2539 Universidade Federal do Rio Grande do Sul, Brasil E-mail: thiagolantmann@hotmail.com.br

Liris Kindlein

ORCID: https://orcid.org/0000-0002-3925-1128 Universidade Federal do Rio Grande do Sul, Brasil E-mail: liris.kindlein.ufrgs@gmail.com

Cristian Pertile Berton

ORCID: https://orcid.org/0000-0003-2385-0174 Universidade Federal do Rio Grande do Sul, Brasil E-mail: cristian.berton@ vibra.com.br

Paula Nunes Tartari

ORCID: https://orcid.org/0000-0002-7089-0470 Internacionalista (autônoma), Brasil E-mail: paulatartari@outlook.com

\begin{abstract}
Resumo
A evolução genética das linhagens de frango de corte desencadeou ganhos nos índices de desempenho e alterações corpóreas. Isto posto, evidencia-se um desafio às indústrias avícolas o cumprimento dos padrões legais dos teores da Relação Umidade:Proteína (RUP) para deter fraudes por inserção de água na carne. Neste sentido, sabe-se que os defeitos musculares de peito amadeirado e estrias brancas influenciam na composição centesimal da carne, identificando-se cortes com maior umidade e menor funcionalidade proteica. Outro fator importante na variação da RUP é o peso das aves, pois quanto menor for a carcaça, maior será sua absorção de água no processo de abate. Por isso, o objetivo da pesquisa foi avaliar a RUP e sua associação com a ocorrência e severidade dos defeitos musculares e a influência do peso dos peitos de frangos de corte nestas variáveis. Coletou-se 240 amostras de peitos de frangos de corte com 42 dias que foram pesadas, classificadas pela severidade dos defeitos musculares e avaliadas para sua composição centesimal de umidade e proteína através de espectroscopia de reflectância do infravermelho proximal (NIRS). Nos resultados verificou-se que a média da RUP apresentou diferença significativa $(\mathrm{p}<0,05)$ na presença de peito amadeirado. Entretanto, os peitos acometidos por estrias brancas não apresentaram diferença na RUP. Em ambos os defeitos, a RUP foi influenciada pelo peso do peito. Portanto, deve-se considerar as mudanças de deposição dos tecidos corporais das linhagens modernas para garantir que os padrões legais sejam eficazes no controle de fraudes e não estejam obsoletos.
\end{abstract}

Palavras-chave: Estrias brancas; Frangos de corte; Peito amadeirado; Peso do peito; Relação Umidade:Proteína (RUP).

\begin{abstract}
The genetic evolution of broiler strains triggered gains in performance indexes and body changes. That said, there is a challenge for the poultry industries to comply with the legal standards of the Moisture:Protein Ratio (MPR) contents to stop fraud by inserting water into the meat. In this sense, it is known that muscle defects such as wooden breast and white striping influence the centesimal composition of the meat, identifying cuts with higher moisture and lower protein functionality. Another important factor in the MPR variation is the weight of the poultry, given that the smaller the carcass, the greater its absorption of water in the slaughter process. Therefore, the aim of this research was to evaluate the MPR and its association with the occurrence and severity of muscle defects, as well as the influence of broiler breast weight on these variables. A total of 240 samples of 42-day-old broiler breasts were collected, weighed, classified by their muscle defects severity, and evaluated for their centesimal composition of moisture and protein through means of near-infrared reflectance spectroscopy (NIRS). It was verified in the results that the mean of the MPR presented a significant difference $(\mathrm{p}<0.05)$ in the presence of the wooden breast. Nonetheless, breasts affected
\end{abstract}


by white striping did not present differences in MPR. In both defects, MPR was influenced by breast weight. Therefore, changes in body tissue deposition of modern strains should be considered to ensure that legal standards are not obsolete, being effective in controlling fraud.

Keywords: Breast weight; Broilers; Moisture:Protein Ratio (MPR); White striping; Wooden breast.

\section{Resumen}

La evolución genética de las líneas de pollos de engorde desencadenó ganancias en los índices de rendimiento y cambios corporales. Dicho esto, existe un desafío para que las industrias avícolas cumplan con los estándares legales del contenido de la relación humedad: proteína (RHP) para disuadir el fraude al insertar agua en la carne. En este sentido, se sabe que los defectos del músculo de la pechuga de madera y las estrías blancas influyen en la composición proximal de la carne, identificándose cortes con mayor humedad y menor funcionalidad proteica. Otro factor importante en la variación de la RHP es el peso de las aves, ya que cuanto menor es la canal, mayor es su absorción del agua en el proceso de sacrificio. Por lo tanto, el objetivo de la investigación fue evaluar el RHP y su asociación con la ocurrencia y severidad de defectos musculares y la influencia del peso de la pechuga de pollos de engorde en estas variables. Se recogieron 240 muestras de pechuga de pollo de 42 días de edad, en seguida estas fueron pesadas, clasificadas por la severidad de los defectos musculares y evaluadas por su humedad próxima y composición proteica por medio de espectroscopía de reflectancia de infrarrojo cercano (NIRS). En los resultados, se verificó que el promedio de la RHP presentó diferencia significativa $(\mathrm{p}<0,05)$ en la presencia de pechuga de madera. Sin embargo, los senos afectados por estrías blancas no demostraron diferencias en RHP. En ambos defectos, la RHP fue influenciada por el peso de la mama. Por lo tanto, se deben considerar cambios en la deposición de tejido corporal de los linajes modernos para garantizar que los estándares legales sean efectivos para controlar el fraude y no sean obsoletos.

Palabras clave: Estrías blancas; Pechuga de madera; Peso de la mama; Pollos de engorde; Relación Humedad:Proteína (RHP).

\section{Introdução}

A cadeia avícola possui grande representatividade no agronegócio nacional, uma vez que o país apresenta-se como uma potência produtiva neste segmento, fazendo com que ocorra um crescimento na busca por alimentos seguros e de qualidade. A carne de frango possui ótima aceitação pelo mercado consumidor mundial e o Brasil se destaca neste cenário por encontrar-se no ranking de maior exportador e o terceiro maior produtor da mesma (ABPA, 2021).

A avicultura brasileira exporta para diversos países desenvolvidos que exigem uma melhoria da qualidade do produto, sendo que o setor avícola representa um dos maiores setores da produção agropecuária no Brasil (Coelho, et al., 2021). Devido a esta relevância econômica, a demanda por alimentos seguros e de qualidade encontra-se cada vez maior. Por isso, o setor avícola vem aumentando sua rigidez em todas as etapas do processo visando evitar qualquer possível dano que atinja o público consumidor da carne de frango.

Dentro desse contexto, encontra-se o aumento de programas e controles oficiais de inocuidade e redução de fraudes por inserção de água em carnes. No entanto, atualmente, as indústrias vêm enfrentando desafios para cumprir as imposições oficiais exigidas para os teores (\%) de Umidade, de Proteína e para a Relação Umidade:Proteína (RUP) determinadas pela Instrução Normativa $\mathrm{N}^{\circ}$ 32, de dezembro de 2010, do Ministério da Agricultura, Pecuária e Abastecimento (MAPA) (Brasil, 2010). Entretanto, deve-se considerar que estes teores podem apresentar variações em seus índices devido a causas multifatoriais, desta forma, estando mais suscetível a extrapolar os limites impostos pela legislação sem quaisquer intenções de fraude.

Segundo Pardi et al. (2006), a absorção de água pode sofrer interferência por muitos fatores, dentre eles o pH elevado, a refrigeração instantânea das carcaças pré rigor mortis, a composição química da carne, a idade, o peso e o tamanho das aves (Sant'anna, 2008). Além disso, os defeitos musculares wooden breast e white striping são uma das causas de perdas econômicas significativas na indústria avícola (Velleman \& Clark, 2015) e de interferência na qualidade química e física da carne. Soglia et al. (2016) identificaram alterações de aumento de umidade, gordura e colágeno, e diminuição de proteína em peitos de frangos acometidos por ambos defeitos.

Diante do exposto, o objetivo da pesquisa foi avaliar a RUP e sua associação com a ocorrência e graus de severidade 
dos defeitos musculares peito amadeirado e estrias brancas e a influência do peso dos peitos de frangos de corte nestas variáveis.

\section{Metodologia}

\subsection{Delineamento experimental}

No presente estudo, foram coletadas ao total 240 amostras de peitos de frangos de corte de linhagem moderna comercial com 42 dias de idade, provenientes de diferentes propriedades criadoras de frango de corte, integradas a um abatedouro-frigorífico localizado na região Sudoeste do estado do Paraná, Brasil.

As amostras foram coletadas de forma aleatória diretamente de diferentes etapas do processo de abate. Sendo estes pontos: 1- Pré-inspeção (sangria); 2- Pós-depenagem; 3- Antes do pré-chiller; 4- Antes do chiller; 5- Após o chiller; 6- Após o gotejamento; 7- Sala de cortes; 8- Produto embalado (24 horas). Além disso, as amostras selecionadas foram provenientes de diferentes turnos de funcionamento do estabelecimento (manhã e tarde), com o objetivo de garantir uma amostragem variada.

\subsection{Análises realizadas - Defeitos musculares e Análises Centesimais}

Após a coleta das amostras, as mesmas foram acondicionadas e direcionadas ao setor de qualidade do abatedourofrigorífico, onde os pesquisadores realizaram as análises pré-estabelecidas.

Para isso, as amostras foram submetidas à pesagem individual e, posteriormente, segregadas em cortes de peito esquerdo e direito.

Definido isto, no peito direito foi realizada a classificação macroscópica segundo o grau de severidade dos defeitos musculares Wooden breast (Sihvo, et al., 2014) (grau 0 = sem lesão; grau 1 = enrijecimento na porção cranial ou caudal do músculo Pectoralis major; grau 2 = enrijecimento difuso; grau 3 = enrijecimento em todo músculo; grau 4 = enrijecido, com petéquias e exsudato) e White striping (Kuttappan, et al., 2012a) (grau $0=$ sem estrias; grau 1 = estrias visíveis com menos de um (1) $\mathrm{mm}$ de espessura; grau 2 = estrias com mais de um (1) $\mathrm{mm}$ de espessura).

Já com relação ao peito esquerdo, realizou-se análise centesimal, em triplicata, do teor de umidade (\%) e de proteína (\%) por espectroscopia de reflectância no infravermelho proximal (NIRS) através do equipamento FoodScan ${ }^{\mathrm{TM}}$ Lab (FOSS, 2012) pré-calibrado para a determinação de umidade, proteínas e lipídios em frangos de corte. A espectroscopia de reflectância no infravermelho próximo é uma técnica moderna, sendo considerado um método rápido e não destrutivo e consiste em um sistema de deteç̧ão que revela a radiação além da região visível do espectro.

\subsection{Análises dos dados}

Os resultados foram analisados e classificados de acordo com os valores estipulados na Instrução Normativa $\mathrm{N}^{\circ} 32$, de 03 de dezembro de 2010 (Brasil, 2010), na qual os parâmetros para a porcentagem de umidade, proteína e a Relação Umidade:Proteína de cortes de peito e meio peito de frango são de 67,16 a 75,40 (\%); 17,81 a 22,05 (\%) e 3,28 a 3,92 (\%), respectivamente.

De acordo com a Instrução Normativa supracitada, os parâmetros para a porcentagem de umidade (\%), proteína (\%) e a relação Umidade:Proteína nos diferentes cortes de frango, estão descritos na Tabela 1. 
Tabela 1. Parâmetro de Umidade e Proteína segundo a IN 32, de 2010 do MAPA.

\begin{tabular}{lllc}
\hline Corte & Umidade (\%) & Proteína (\%) & Umidade:Proteína \\
\hline Peito e meio peito & 67,16 a 75,40 & 17,81 a 22,05 & 3,28 a 3,92 \\
Peito sem pele & 73,36 a 75,84 & 21,05 a 24,37 & 3,03 a 3,55 \\
Coxa com sobrecoxa & 62,82 a 70,70 & 14,36 a 18,08 & 3,59 a 4,67 \\
\hline
\end{tabular}

Fonte: Dias, et al., 2016.

\subsection{Análises Estatísticas}

Os dados foram submetidos à análise estatística e utilizou-se o Teste $\mathrm{T}$ para comparação das médias das amostras independentes. A normalidade para a realização do teste $T$ foi avaliada através do teste Shapiro-Wilk. Além disso, foi utilizada a ANOVA para avaliar a presença de diferentes graus de severidade dos defeitos musculares (peito amadeirado e estrias brancas) quanto à média da Relação Umidade:Proteína e do peso final do corte comercial.

Todas as análises foram realizadas utilizando o software Statistical Analysis System (SAS, 2012) com nível de significância de $5 \%$.

\section{Resultados}

Os resultados obtidos demonstram que a comparação dos valores médios da Relação Umidade:Proteína (RUP) e do peso dos peitos de frangos com o defeito muscular Wooden Breast, apresentaram diferenças significativas $(\mathrm{p}<0,05)$ entre os diferentes graus de severidade da lesão para ambas as variáveis.

Ao realizar as análises de comparações múltiplas, observou-se que a RUP não demonstrou diferença significativa entre a ausência do defeito muscular na carcaça (grau 0) e a presença do mesmo, independente da severidade (graus 1, 2, 3 e 4). Porém, na presença da lesão no peito da carcaça, pôde-se verificar diferença significativa da RUP conforme o grau do peito amadeirado. Foi constatado que o grupo onde a lesão caracterizava-se de forma mais branda (graus 1 e 2) não houve diferença significativa entre os mesmos, assim como no grupo com lesões moderadas e graves (graus 3 e 4 ) que demonstraram o mesmo comportamento.

Além disso, pôde-se constatar que os maiores valores médios para a RUP correspondiam às carcaças que apresentaram a lesão e em graus mais severos (grau 3 e 4).

Em relação as médias de peso por categoria de lesão, o mesmo comportamento foi observado, onde observou-se uma maior média conforme o grau do defeito apresentou-se mais severo (Tabela 2). 
Tabela 2. Valores médios da Umidade (\%), Proteína (\%), Relação Umidade:Proteína (RUP), e do peso (g) dos peitos de frangos acometidos com diferentes graus de severidade de Wooden Breast (WB).

\begin{tabular}{|c|c|c|c|c|c|}
\hline GRAU WB & $\mathbf{N}$ & UMIDADE & PROTEÍNA & RUP & PESO \\
\hline $\mathbf{0}$ & 34 & 75,78 & 17,81 & $4,26^{\mathrm{a}}$ & $200,47^{\mathrm{ac}}$ \\
\hline 1 & 61 & 75,70 & 17,63 & $4,29^{\mathrm{ab}}$ & $235,02^{b c}$ \\
\hline 2 & 65 & 75,64 & 17,90 & $4,23^{\mathrm{ab}}$ & $257,68^{\mathrm{b}}$ \\
\hline 3 & 39 & 75,84 & 17,25 & $4,39^{\mathrm{ac}}$ & $277,00^{\text {bc }}$ \\
\hline 4 & 41 & 75,91 & 17,45 & $4,35^{\mathrm{ac}}$ & $277,02^{\mathrm{bc}}$ \\
\hline TOTAL & 240 & - & - & - & - \\
\hline P-VALOR & & & & $\mathbf{0 , 0 3 5}$ & ,000 \\
\hline
\end{tabular}

Grau 0 = sem lesão; Grau 1 = enrijecimento na porção cranial ou caudal do músculo Pectoralis major; Grau 2 = enrijecimento difuso; Grau 3 = enrijecimento em todo músculo; Grau 4 = enrijecido, com petéquias e exsudato. Se p-valor $<0,05$, conclui-se que existe uma diferença significativa. Fonte: Sihvo, et al., 2014. ${ }^{\mathrm{a}, \mathrm{b}, \mathrm{c}}$ Valores seguidos por letras distintas diferem significativamente pelo teste de Tukey $(\mathrm{p} \leq 0,05)$. Fonte: o próprio autor.

No que diz respeito aos valores médios da RUP relacionada aos diferentes graus de severidade de White Striping, não apresentaram diferenças significativas entre estas variáveis.

Enquanto para a média do peso e sua associação com os graus de severidades do mesmo defeito muscular, houve diferenças significativas $(\mathrm{p}<0,05)$ entre todos os diferentes graus de severidade de lesões do peito com estrias brancas. Complementar a isto, pode-se verificar uma média crescente do peso concomitante ao aumento do grau da lesão (Tabela 3 ).

Tabela 3. Valores médios da Umidade (\%), Proteína (\%), Relação Umidade:Proteína (RUP), e do peso (g) dos peitos de frangos acometidos com diferentes graus de severidade de White Striping (WS).

\begin{tabular}{|c|c|c|c|c|c|}
\hline GRAU WS & $\mathbf{N}$ & UMIDADE & PROTEÍNA & RUP & PESO \\
\hline $\mathbf{0}$ & 19 & 75,89 & 17,61 & 4,31 & $191,63^{\mathrm{a}}$ \\
\hline 1 & 78 & 75,67 & 17,79 & 4,26 & $237,49^{b}$ \\
\hline 2 & 143 & 75,78 & 17,56 & 4,32 & $265,01^{\mathrm{c}}$ \\
\hline TOTAL & 240 & - & - & - & - \\
\hline P-VALOR & & & & 0,062 & ,000 \\
\hline
\end{tabular}

Grau 0 = sem estrias; Grau 1 = estrias visíveis com menos de um (1) mm de espessura; Grau 2 = estrias com mais de um (1) mm. Se pvalor $<0,05$, conclui-se que existe uma diferença significativa. Fonte: Kuttappan, et al., 2012a. a,b,c Valores seguidos por letras distintas diferem significativamente pelo teste de Tukey $(\mathrm{p} \leq 0,05)$. Fonte: o próprio autor.

\section{Discussão}

Ao decorrer da linha de abate há diversos processos envolvendo lavagens as quais as carcaças são submetidas, podendo ocorrer absorção ou perda de água devido a troca da mesma através das fibras musculares. Esta adição de água exógena à água fisiológica é tecnicamente inevitável e, por isso, é conhecida e aceita, desde que se encontre dentro do que é previsto nos limites da legislação. Desta forma destaca-se a importância do monitoramento constante, para que não haja 
excedentes prejudicando economicamente o consumidor (Brasil, 1998).

Nesse sentido, em um estudo realizado em países da Europa (European Comission, 2012), as carcaças de frangos de corte avaliados em 2012 apresentaram maior conteúdo de água e menor teor de proteína do que os criados em 1993. Observações semelhantes também foram realizadas no Brasil (Figueiredo, et al., 2016). Estes estudos indicam que a possível razão para esses valores resida nos contínuos programas de seleção genética que alteram a composição da carcaça dos frangos de corte e seus respectivos teores de água e proteína. Considerando-se a dinamicidade do processo genético, é sensato que haja conferência de maneira periódica dos limites de intervalos dos valores legais e compará-los aos dados fisiológicos dos frangos de corte atuais. Corroborando com o estudo, a presente pesquisa indica tendências de que a legislação em vigor no Brasil possa não estar mais adequada ao frango de corte comercial e sua respectiva carga genética e fisiológica que há disponível atualmente, uma vez que não houve correspondência entre os limites aceitáveis pela legislação vigente e os teores da Relação Umidade:Proteína (RUP) apresentados na pesquisa. O mesmo padrão manteve-se para a maioria dos resultados de teor de Umidade, no qual encontravam-se acima do limite determinado e, também, para os teores de Proteína que demonstraram uma não conformidade com os limites pré-estabelecidos, apresentando valores inferiores ao estipulado.

Também foi demonstrado nesta pesquisa que a presença e a severidade do peito amadeirado influenciam significativamente na média da RUP e que as maiores médias são encontradas nos graus mais graves da lesão, concordando com outros pesquisadores (Mudalal, et al., 2014) que identificaram em peitos amadeirados menores teores de proteína e cinzas, maior percentagem de umidade, colágeno e gordura intramuscular, bem como menor funcionalidade proteica. Além disso, houve diferenças significativas entre os diferentes graus de severidade deste defeito quando comparados aos valores médios do peso dos peitos e, também, observou-se que as médias apresentaram valores crescentes conforme o grau de severidade se tornava mais severo. Dados similares foram verificados por Berri et al., (2007) que comprovam que o maior rendimento do peito de frango está relacionado com o aumento dos defeitos musculares e modificações na qualidade muscular. Ademais, sabe-se que o peso ou o tamanho das aves são fatores relevantes que podem variar o teor de absorção de água pelas carcaças, pois quanto menor for a mesma, maior será a sua porcentagem de absorção (Obdam, 2005).

Além disso, observou-se no presente estudo que a presença e a gravidade de lesão de estrias brancas não influenciaram nos valores médios da RUP nos peitos de frangos. Discordando de pesquisadores que identificaram aumento de umidade, gordura e colágeno e diminuição no teor de proteína, em peitos de frangos acometidos por white striping (Soglia, et al., 2016). Ainda com relação a este defeito muscular, os resultados da média do peso foram significativamente associados entre todos os diferentes graus de severidades e essa média foi crescente concomitantemente ao aumento da gravidade das lesões. Esses dados corroboram com estudos que concluíram ser mais provável a incidência de graus mais elevados de peitos defeituosos em aves mais pesadas e com maior taxa de crescimento (Kuttappan, et al., 2012b; Kuttappan, et al., 2013). Os resultados obtidos no estudo também corroboram com outros pesquisadores (Bauermeister, et al., 2009) que verificaram o aumento da ocorrência e da severidade deste defeito com o aumento do peso dos filés de peito.

Portanto, se a legislação tem como objetivo evitar as crescentes fraudes relacionadas à adição de água exógena aos produtos, deve considerar a possibilidade da evolução genética do frango e a sua respectiva alteração da composição corporal da carcaça, além das variáveis demonstradas no estudo e suas devidas alterações e influências na qualidade e teores centesimais da carne. Sendo assim, mesmo que as empresas e indústrias avícolas assegurem um rígido controle de qualidade durante todo o processamento de abate, torna-se cada vez mais difícil cumprir os parâmetros da lei sem exceder os limites estabelecidos que parecem estar obsoletos. 


\section{Conclusão}

A presente pesquisa concluiu que os valores médios da Umidade e Proteína, bem como da Relação Umidade:Proteína (RUP) não apresentaram-se em conformidade com a legislação vigente.

Além disso, pode-se determinar que a média da RUP, juntamente com a variável peso dos peitos de frangos, têm diferença significativa quando comparadas a presença e a severidade do defeito muscular Wooden Breast, ao contrário do que ocorre com a média RUP relacionada à presença e gravidade de White Striping, onde não houve a presença de qualquer diferença. No entanto, determinou-se que a média do peso e os diferentes graus de estrias brancas obtiveram associação significativa entre si.

Por fim, torna-se necessário e de extrema importância que sejam realizados estudos futuros nos quais incluam amostragens representativas das carcaças e de cortes comerciais de frangos de corte, considerando a fisiologia dos animais produzidos no Brasil atualmente. Para que, desta maneira, possa realizar-se uma determinação da Relação Umidade:Proteína e que esta consiga proporcionar um embasamento técnico-científico para a legislação nacional.

\section{Agradecimentos}

Ao apoio prestado pelos colaboradores do frigorífico durante todo o período experimental.

\section{Referências}

ABPA - Associação Brasileira de Proteína Animal. (2021). Relatório Anual 2021. http://abpa-br.org/mercados/\#relatorios

Bauermeister, L. J., A. U. Morey, E. T. Moran, M. Singh, C. M. Owens, \& S. R. McKee. (2009). Occurrence of white striping in chicken breast fillets in relation to broiler size. Poulry Science. 88(Suppl. 1):33 (Abstr.).

Berri, C., Le Bihan-Duval, E., Debut, M., Sante-Lhoutellier, V., Baeza, E., Gigaud, V., Jego, Y. \& Duclos, M. J. (2007). Consequence of muscle hypertrophy on characteristics of pectoralis major muscle and breast meat quality of broiler chickens. Journal of Animal Science, 85(8), $2005-2011$.

Brasil. Ministério da Agricultura Pecuária e Abastecimento. (1998). Portaria $n^{\circ} 210$, de vinte e seis de novembro de 1998, que aprova o Regulamento Técnico de Inspeção Tecnológica e HigiênicoSanitária de Carnes de Aves e estabelece as metodologias de análises e seus parâmetros, apresentando como atividade básica do Serviço de Inspeção Federal (SIF).

Brasil. Ministério da Agricultura Pecuária e Abastecimento. (2010). Instrução Normativa $n^{\circ}$ 32, de vinte e seis de julho de 2010, que Estabelece os parâmetros para avaliação do Teor Total de Água Contida nos Cortes de Frangos, resfriados e congelados.

Coelho, A. E. G., Domingues, J. A. G., \& Silva, E. J. (2021). Exportação brasileira do frango de corte. Revista Processando O Saber, 13, 124-137. Recuperado de https://www.fatecpg.edu.br/revista/index.php/ps/article/view/161

Dias, V. H. C., Kovacs, T. A. S., Herrera, R. A., dos Santos, T. G., dos Santos, J. M. G., Andreazzi, M. A. (2016). Relação Umidade:Proteína nas carcaças de frango de corte. In: VIII Mostra Interna de Trabalhos de Iniciação Científica. I Mostra Interna de Trabalhos de Iniciação Tecnológica e Inovação. 2016, Maringá, PR. Anais... Maringá: UniCesumar, 2016. https://www.unicesumar.edu.br/mostra-2016/wp-content/uploads/sites/154/2017/07/victor_hugo_cortezdias.pdf

European Comission. (2012). http://ec.europa.eu/agriculture/external-studies/2012/water-inpoultry/fulltext_en.pdf

Figueiredo, E. A. P., Krabbe, E. L., Avila, V. S. De., Klein, C. H., Lopes, L. Dos S. \& Kawski, V. L. (2016). Relação umidade: proteína em genótipos de frangos de corte. In: Conferência Apinco de Ciência e Tecnologia Avícolas, 2016, Campinas, SP. Anais... Campinas: FACTA, 2016. http://www.alice.cnptia.embrapa.br/alice/handle/doc/1054844

FOSS. FoodScan ${ }^{\mathrm{TM}}$ for meat. User Manual. (2012). FOSS Analytical A/S, Hillerod, Denmark. https://pdf.directindustry.com/pdf/foss-analytical/foodscanmeat/34361-631374.html

Kuttappan, V. A.; Brewer, V. B.; Apple, J. K.; Waldroup, P. W. \& Owens, C. M. (2012a). Influence of growth rate on the occurrence of white striping in broiler breast fillets. Poultry Science, 91(10), 2677-2685. https://doi.org/10.3382/ps.2012-02259

Kuttappan, V. A.; Lee, Y. S.; Erf, G. F.; Meullenet, J.-F. C.; Mckee, S. R. \& Owens, C. M. (2012b). Consumer acceptance of visual appearance of broiler breast meat with varying degrees of white striping. Poultry Science, 91(5), 1240-1247. https://doi.org/10.3382/ps.2011-01947

Kuttappan, V. A., Brewer, V. B., Mauromoustakos, A., Mckee, S. R., Emmert, J. L., Meullenet J. F. \& Owens, C. M. (2013). Estimation of factors associated with the occurrence of WS in broiler breast fillets. Poultry Science, 92, 811-819.

Mudalal, S., Babini, E., Cavani, C., \& Petracci, M. (2014). Quantity and functionality of protein fractions in chicken breast fillets affected by white striping. Poultry Science, 93(8), 2108-2116. https://doi.org/10.3382/ps.2014-03911 
Research, Society and Development, v. 11, n. 2, e31711225789, 2022

(CC BY 4.0) | ISSN 2525-3409 | DOI: http://dx.doi.org/10.33448/rsd-v11i2.25789

Obdam, J. (2005). Resfriamento de carcaça de aves em ar ou água - implicações microbiológicas e de qualidade da carne. https://ital.agricultura.sp.gov.br/ctc/eventos/terceiro_congresso/3.doc

Pardi, M. C., dos Santos, I. F., de Souza, E. R. \& Pardi, H. S. (2006). Ciência, higiene e tecnologia da carne: ciência e higiene da carne. Tecnologia da sua obtenção e transformação. 2. ed., rev. ampl. Goiânia: UFG, 2006, 1, 623 p.

Sant'anna. V. Análise dos fatores que afetam a temperatura e absorção de água em carcaças de frango em chiller industrial. (2008). $54 \mathrm{f}$. Monografia (Graduação em Tecnologia de Alimentos) - Universidade Federal do Rio Grande do Sul, Porto Alegre, 2008.

SAS. (2012). Statistical Analysis System. User's Guide: Statistical. Version 9.1th ed. SAS. Inst. Inc. Cary. N.C. USA.

Sihvo, H. K.; Immonen, K.; \& Puolanne, E. (2014). Myodegeneration With Fibrosis and Regeneration in the Pectoralis Major Muscle of Broilers. Veterinary Pathology, 51(3), 619-623.

Soglia, F., Laghi, L., Cananico, L., Cavani, C. \& Petracci, M. (2016). Functional property issues in broiler breast meat related to emerging. Food Research International, 89(3), 1071-1076. https://doi.org/10.1016/j.foodres.2016.04.042

Velleman, S. G., \& Clark, D. L. (2015). Histopathologic and Myogenic Gene Expression Changes Associated with Wooden Breast in Broiler Breast Muscles. Avian Diseases, 59(3), 410-418. https://doi.org/10.1637/11097-042015-Reg.1. 